\title{
An overview on the treatment strategies of non-displaced femoral neck fracture in the elderly
}

Yangyang Zhou ${ }^{1,2,3,4,5+}$, Yuanwei Zhang ${ }^{1,2,3,4,5+}$, Panpan Lu $u^{1,2,3,4,5}$, Hui Chen ${ }^{1,2,3,4,5}$, Ming Ni ${ }^{6^{*}}$ and Yunfeng Rui ${ }^{1,2,3,4,5^{*}}$ (1)

\begin{abstract}
Background: This paper aimed to review the databases on non-displaced femoral neck fractures in elderly patients. We also discussed the surgical and non-surgical treatments and selection of implants.

Methods: Reviewed was the literature on non-displaced femoral neck fractures in elderly patients. Four major medical databases and a combination of the search terms of "femoral neck fractures", "nondisplaced", "undisplaced", "nondisplaced", "un-displaced", "aged", "the elderly", and "geriatric" were used to search the literature relevant to the topic of the review.

Results: Patients who were unable to tolerate the operation and anesthesia could be treated conservatively. Otherwise, surgical treatment was a better choice. Specific surgical strategies and implant selection were important for the patient's functional recovery.

Conclusions: The non-displaced femoral neck fractures are relatively stable but carry a risk of secondary displacement. Surgical treatments may be a better option because the implants provide additional stability and allow early exercise and ambulation. Hemiarthroplasty is also an alternative for old patients with higher risks of displacement and avascular necrosis of the femoral head.
\end{abstract}

Keywords: Elderly, Non-displaced, Femoral neck fracture, Conservative treatment, Internal fixation, Hemiarthroplasty

\section{Introduction}

The femoral neck fracture is one of the most common fractures in the elderly, which seriously threatens and affects the patients' health and quality of life [1, 2]. Currently, the optimal strategy for the treatment of non-displaced femoral neck fractures (NDFNFs) is still debated $[1,2]$.

\footnotetext{
*Correspondence: niming301@163.com; ruiyunfeng@126.com

†Yangyang Zhou and Yuanwei Zhang contributed equally to this work.

${ }^{1}$ Department of Orthopedics Zhongda Hospital, School of Medicine

Southeast University, NO. 87 Ding Jia Qiao, Nanjing 210003, Jiangsu, China

${ }^{6}$ Department of Orthopedics the First Medical Center, Chinese PLA General Hospital, No. 28 Fuxing Road, Beijing 100853, China

Full list of author information is available at the end of the article
}

The femoral neck fractures are classified into Garden type I and II (NDFNFs) and Garden type III and IV (displaced femoral neck fractures) (Table 1). The NDFNFs are prone to re-displacement, resulting in a fracture healing rate of $44.3 \%$ and a postoperative re-displacement rate of $33 \%$ to $44 \%[3,4]$. Therefore, surgical treatments may be a better option for the elderly [5]. Internal fixation and joint replacement are two surgical strategies, and the choice of implants and prostheses selection are at issue [6].

This paper aimed to review the databases on NDFNFs in elderly patients. We also discussed their surgical and non-surgical treatments and selection of implants. original author(s) and the source, provide a link to the Creative Commons licence, and indicate if changes were made. The images or other third party material in this article are included in the article's Creative Commons licence, unless indicated otherwise in a credit line to the material. If material is not included in the article's Creative Commons licence and your intended use is not permitted by statutory regulation or exceeds the permitted use, you will need to obtain permission directly from the copyright holder. To view a copy of this licence, visit http://creativecommons.org/licenses/by/4.0/. 
Table 1 Detailed rules of Garden classification of the femoral neck fracture

\begin{tabular}{cl}
\hline Garden type & Characteristics \\
\hline I & Incomplete fracture: The fracture line does not pass through the whole femoral neck, there is partial bone connec- \\
tion in the femoral neck, the fracture has no displacement, and a certain blood supply is maintained at the proximal \\
fracture end. \\
Complete fracture without displacement: Although the femoral neck was completely broken, it is well aligned. If it is \\
a fracture under the femoral head, it may still heal, but the probability of ONFH is high. If it is a fracture of the middle \\
or basal part of the femoral neck, the fracture is easy to heal and the blood supply of the femoral head is appreciable. \\
Complete fracture with partial displacement: Mostly, the distal end of the fracture is displaced upward or the lower \\
corner of the distal end of the fracture is inserted into the proximal section, resulting in the inward rotation and \\
displacement of the femoral head, and the neck shaft angle becomes smaller. \\
Complete fracture with complete displacement: The proximal end of the fracture can be rotated, and the distal end \\
in mostly shifted back and upward. The joint capsule and synovium are severely damaged, and the blood vessels \\
supplying the femoral head via the joint capsule and synovial membrane are also easily damaged, resulting in ONFH.
\end{tabular}

ONFH, osteonecrosis of femoral head

\section{Materials and Methods}

We searched PubMed, ScienceDirect, Scopus, and Embase by using the terms "femoral neck fractures", "nondisplaced", "undisplaced", "non-displaced", "un-displaced", "aged", "the elderly", and "geriatric". All relevant titles and abstracts were reviewed. We read the full articles in the scope of the stated purposes, and the information supporting this review article was extracted.
The flow chart depicting the strategy for selecting the relevant research is presented in Fig. 1.

Our inclusion criteria included: (1) clinical research; (2) patients with femoral neck fracture; (3) patients aged above 65 years old; (4) type I or II femoral neck fractures against the Garden classification; (5) clinical interventions including conservative treatments, internal fixation, and joint replacement. The exclusion criteria were: (1) duplicate publications; (2) patients with a failed
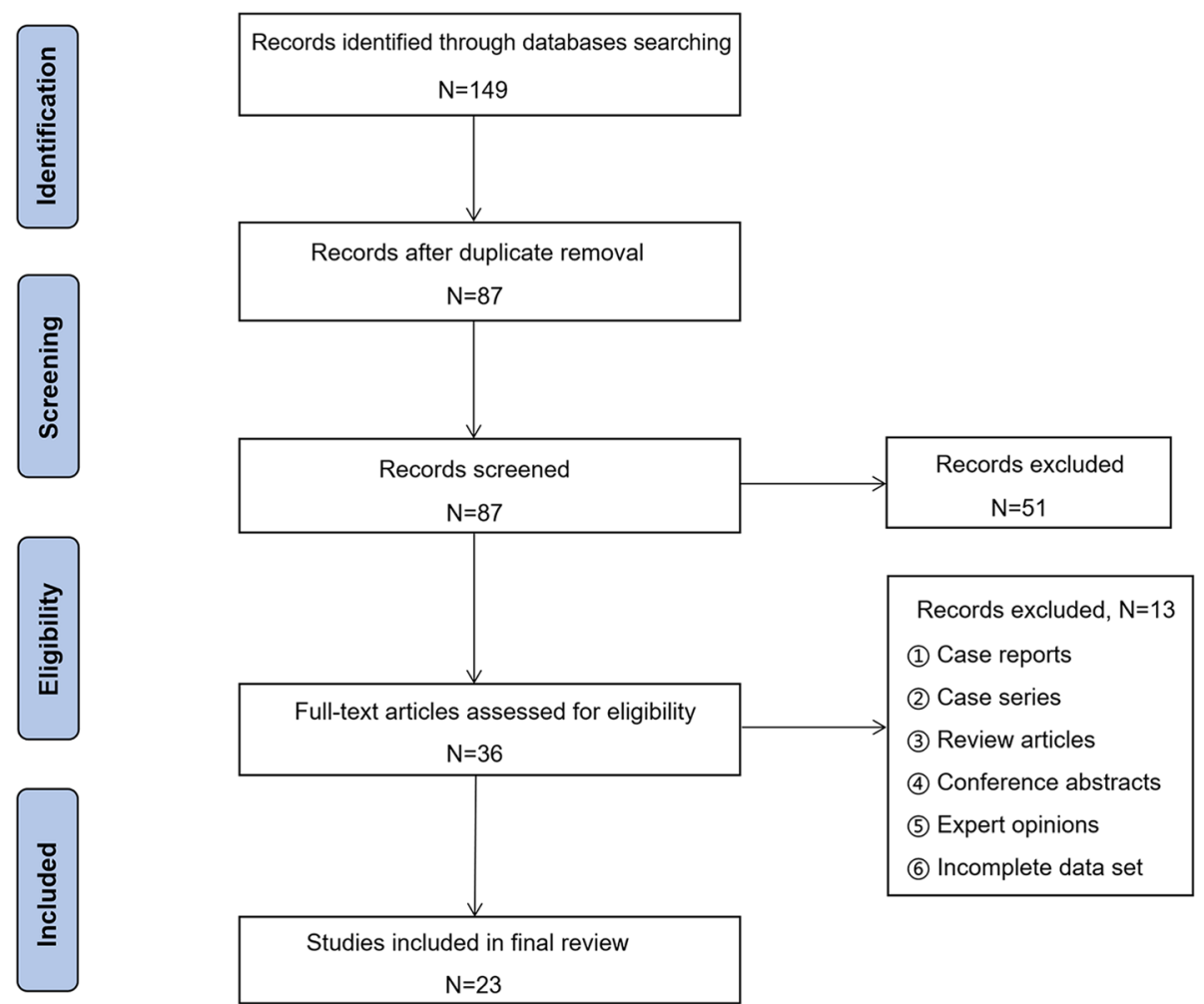

Fig. 1 Flow chart depicting the strategy used to select the relevant research 
internal fixation or revision operation after the initial joint replacement; (3) preoperative heart failure or mental disorder; (4) old or pathological fractures and rheumatoid arthritis; (5) the inconsistent outcome indicators.

\section{Results}

A total of 149 articles were included in the retrieval process, and the records after duplicate removal were 87 . Furthermore, after excluding the case reports, case series, review articles, conference abstracts, expert opinions and incomplete data sets, a total of 23 full-text articles were ultimately included in the final review.

\section{Conservative treatment}

Both Garden type I and II fractures are NDFNFs. Garden type I fractures can be treated conservatively, but misdiagnosis and osteoporosis may lead to secondary displacement [7]. The complication rate of type II fractures is 1.5 times higher than that of type I fractures. In a recent retrospective study, Rzesacz et al [8] revealed that conservative treatments were associated with a higher complication rate as compared to surgical treatments. Therein, the incidence of complications in the conventional treatment group was as high as $30-40 \%$. Moreover, Cserhati et al [9] also revealed that the complication rate, especially the osteonecrosis of femoral head (ONFH), after conservative treatment was $18.9 \%$, which was much higher than that of surgical treatment (3.2\%). Since NDFNFs also involve fracture lines, the CT scan shows the pattern of the fracture more clearly for treatment plan. In addition, compared with the use of Garden classification alone, it is more effective to combine the three-dimensional (3D) reconstruction of hip joint with Garden classification to fully evaluate the NDFNFs. With the advantages of intuitive and multiple-angle vision, 3D reconstruction can display the anatomical shape of the femoral neck and is superior to X-ray in diagnosis and displacement judgment of fracture. The 3D reconstruction of hip joint can be used to reconstruct the exact status of fracture, so as to assist the surgeons to judge the fracture type according to the Garden classification and provide scientific basis for the development of treatment plan and assessment of prognosis [10-12].

Compared to the surgical treatments, conservative treatments are associated with much more mobility restrictions, bed-related complications, family care, etc, which increase the total cost, morbidity, and mortality $[8$, $9,13]$.

\section{Surgical treatment}

Surgical treatments mainly include internal fixation and joint replacement (especially hemiarthroplasty or total arthroplasty), which are systematically reviewed and summarized in the following sections.

\section{Internal fixation \\ Timing of internal fixation}

Kim et al [14] studied the timing at which patients underwent the internal fixation. Among 58 patients with a mean age of 74 years, the 1-year mortality rate in the patients who had undergone the internal fixation within $24 \mathrm{~h}$ after admission was only $4.7 \%$, which was lower than in patients undergoing internal fixation $24 \mathrm{~h}$ after admission (13.3\%). The 1 -year mortality rate was $7 \%$ in patients who underwent the internal fixation within $48 \mathrm{~h}$ after the admission, and $72 \%$ of the patients recovered their walking ability to their pre-fracture level. Thus, an internal fixation performed shortly after admission (within $48 \mathrm{~h}$ after admission) may achieve better clinical outcomes and have fewer complications, such as nonunion and late segmental collapse of the femur.

\section{Implant Selection}

Many implants are used for treating NDFNFs, including cannulated screws, cancellous bone screws, dynamic hip screws, targon system, emerging dynamic locking plates, and full-thread headless compression screws. The posterior retroversion angle is closely related to the prognosis of the patients with NDFNFs. The retroversion of femoral head and frequently associated comminution of the posterolateral wall compromise blood supply of the femoral head [15, 16]. Palm et al [17] reviewed 113 patients with NDFNFs. One year after surgery, 25 patients (22\%) had a posterior retroversion angle of femoral head more than $20^{\circ}$, and the failure rate of internal fixation was $56 \% ; 78 \%$ of patients had a posterior retroversion angle less than $20^{\circ}$, and the failure rate of internal fixation was $14 \%$. The increased posterior retroversion angle is a risk factor for the re-operation of femoral neck fractures. Besides, Yamamoto et al [18] also suggested that some NDFNFs on X-ray may combine with the posterior retroversion angle of more than $20^{\circ}$ on CT images. The posterior retroversion angle of more than $20^{\circ}$ is intimately related to the poor prognosis of femoral neck fractures.

Cannulated screw is one of the ideal choices for the fixation of NDFNFs in elderly. Chen et al [19] treated 37 patients (over 80 years old) with NDFNFs using cannulated screws. Two years after surgery, the total healing rate was $95 \%$, and the total success rate was $84 \%$. The main reasons for revision were the failure of internal fixation, nonunion of fracture, and ONFH $[20,21]$. Moreover, the high frequency of revision was also related to the factors such as poor bone quality in the elderly, severe osteoporosis, and surgical techniques [22]. 
Fixation with the cancellous bone screw is also one of safe and effective surgical approaches. Lee et al [23] conducted a retrospective study on 116 elderly patients who were treated with cancellous bone screws. Two years after surgery, $85 \%$ of the patients recovered to pre-injury activity level, and $90 \%$ of patients had no pain. In a retrospective study, Manohara et al [24] found that $90 \%$ of patients could independently walk postoperatively, $20 \%$ of patients felt pain during exercise, and the nonunion rate was 3\%. Chiu et al [25] also showed that the non union rate of NDFNFs in patients treated with cancellous bone screws was only $2 \%$.

Dynamic hip screws effectively treat NDFNFs with few complications and a low re-operation rate. Compared to the cannulated screws, patients treated with dynamic hip screws had a higher Harris score one year after surgery and a lower re-operation rate [25, 26]. Watson et al [27] conducted a comparative study on 62 patients treated with dynamic hip screws and cancellous bone screws, and there were six deaths (19.3\%) in both groups. The reoperation rate (3.2\%) was lower in the dynamic hip screw group than in the cancellous bone screw group (10.3\%). In addition, Makki et al [28] studied elderly patients aged 70 on average and found that compared to the dynamic hip screws alone, dynamic hip screws combined with anti-rotation screws may not reduce the incidence of $\mathrm{ONFH}$ and revision rate.

Recent studies have revealed that those systems were associated with a low incidence of postoperative complications in NDFNFs [29]. Compared to traditional screws, the targon system is associated with a lower revision rate and prevents femoral neck-head fragment settlement. Moreover, compared to the cannulated screws (48.8\%), the revision rate of targon system within the first postoperative year is $4.7 \%$ [30]. Compared to the dynamic hip screws, the targon system is associated with low rates of femoral neck-head fragment settlement and fewer hemiarthroplasty due to fixation failure [31]. In addition to the targon system, the emerging dynamic locking plate is also widely used. Van Walsum et al [32] used emerging plates for NDFNFs and found that only 6 cases failed among 149 cases.

Most patients experienced the postoperative femoral neck shortening, resulting in the varus hip and poor gait function. Chiang et al [33] treated 50 NDFNFs using partially-threaded cannulated screws and full-threaded headless compression screws. The two implants provide stable fixation but cannot prevent femoral neck shortening and varus displacement.

\section{Dynamic magnetic resonance imaging (MRI) and surgical selection}

In NDFNFs, nonunion and late collapse of the femoral head are the two major complications. Patients aged 69 or younger have a high risk of ONFH after percutaneous screw fixation [34]. Moreover, preoperative traction also increases the risk of postoperative ONFH [35]. The blood supply to the femoral head is a significant factor affecting fracture healing. Morimoto et al [36] examined blood perfusion of the femoral head using dynamic MRI enhanced integral color imaging and classified the perfusion states into four types. With type A, the color of fracture area was consistent with that of the healthy side, indicating that its blood perfusion was the same; with type $\mathrm{B}$, the color of the fracture area was darker than the femoral head area of the healthy side, indicating that the blood perfusion was reduced; with type $\mathrm{C}$, the fracture area was black, indicating that there was no perfusion in this area. When they treated their patients with three cannulated screws, the nonunion rates of type $\mathrm{A}$, $\mathrm{B}$, and $\mathrm{C}$ were $0,6.7 \%$, and $50.0 \%$, respectively, and the collapse rates of the femoral head were $0,4.4 \%$, and 0 , respectively. For type $\mathrm{C}$ blood perfusion, joint replacement should be the first option, and a revision operation should be avoided if all possible.

\section{Hemiarthroplasty}

In recent years, hemiarthroplasty is increasingly performed in elderly NDFNFs. According to the statistics of the Norwegian fractures data center, NDFNF patients treated with hemiarthroplasty rose from $2.1 \%$ in 2005 to $9.7 \%$ in 2014 [37].

Although different types of internal fixation have been widely acknowledged in the treatment of NDFNFs, Lin et al [38] found that the revision, nonunion and delayed union rates were higher in patients over 75 years old with femoral neck fracture receiving internal fixation than in those with hemiarthroplasty, and the prognosis was also worse. Lu et al [39] conducted a randomized controlled trial comparing hemiarthroplasty and internal fixation for NDFNFs in 78 patients (aged 85 to 100 years). The reoperation rate of the hemiarthroplasty was significantly lower than that of internal fixation (5.41\% vs. 21.4\%). Only the surgical methods had a significant impact on the occurrence of re-operation as shown by a Cox proportional hazard regression model. There were no significant differences between the two treatments in survival time and mean Harris score 5 years after surgery. However, hemiarthroplasty resulted in a significantly higher excellent-to-good rate. In addition, given nearly onethird of the elderly patients have combined dementia, following the postoperative rehabilitation instructions 
is difficult. Therefore, internal fixation may be a better choice in these patients [40].

Regarding this, Olofsson et al [41] conducted a retrospective study including 180 elderly patients (all aged above 70 years) with NDFNFs and dementia. They found no difference in the incidences of complications and mortality at 4 months and 1 year of follow-ups after the internal fixation and hemiarthroplasty. Dementia may not be a contraindication for hemiarthroplasty. Moreover, because the artificial femoral heads gradually degenerate, the postoperative survival of the autologous femoral head may be longer [42-44]. Currently, however, no study has compared the long-term outcomes between artificial and autologous femoral heads.

\section{Controversies on the choice of surgical methods}

Currently, the optimal treatment for NDFNFs is still controversial because few RCTs with a high level of evidence were conducted. The major considerations include postoperative function, complications, reoperation rate, and total cost [26, 34, 45-47]. You et al [48] indicated that internal fixation was associated with mild pain and better patient satisfaction but was associated with a high re-operation rate (20\%). Moreover, hemiarthroplasty was a cost-effective option compared to internal fixation $(\$ 23,467$ vs. $\$ 25,356)$ [47]. Hemiarthroplasty was also associated with less complications, lower re-operation rate, and better early functional recovery [46]. However, the downsides include longer operative time, more intraoperative blood loss, and higher intraoperative risk [4850]. Dolatowski et al [26] conducted an RCT and revealed that hemiarthroplasty didn't outperform internal fixation in the re-establishment of the postoperative hip function. However, we believe that, with rapid development of IT technologies, 3D printing, computer-assisted navigation and other new technologies will find their application in orthopedic practice [51-56]. 3D printing-related personalized technology and the computerized navigation might offer effective solutions to the selection of surgical methods for the NDFNFs in the elderly.

\section{Conclusions and perspectives}

The NDFNFs are relatively stable but carry a risk of secondary displacement. Surgical treatments may be a better option because the implants provide additional stability and allow early exercise and ambulation. Hemiarthroplasty is an alternative treatment for elderly patients with higher risks of displacement and avascular necrosis of femoral head.
Abbreviations

NDFNFs: Non-displaced femoral neck fractures; ONFH: Osteonecrosis of femoral head; MRI: Magnetic resonance imaging; 3D: Three-dimensional; RCTs: Randomized controlled trials; IT: Information technology.

\section{Acknowledgements}

Not applicable

\section{Authors' contributions}

Conceptualization: Yunfeng Rui, Ming Ni, Hui Chen. Data curation: Yangyang Zhou, Panpan Lu. Data analysis: Yangyang Zhou, Panpan Lu. Investigation: Yunfeng Rui, Hui Chen. Methodology: Yangyang Zhou, Yunfeng Rui. Project administration: Yunfeng Rui, Ming Ni. Preparation of original draft: Yangyang Zhou. Writing, review and revision: Yangyang Zhou, Panpan Lu, Yuanwei Zhang, Hui Chen, Ming Ni, Yunfeng Rui. All authors read and approved the final manuscript.

Funding

This research did not receive any specific grant from funding agencies in the public, commercial, or not-for-profit sectors.

Availability of data and materials

The datasets used and/or analyzed during the current study are available from the corresponding author on reasonable request.

\section{Declarations}

Ethics approval and consent to participate

Not applicable

Consent for publication

Not applicable

\section{Competing interests}

The authors declare that they have no competing interests and they were not involved in the journal's review of or decisions related to this manuscript.

\section{Author details}

${ }^{1}$ Department of Orthopedics Zhongda Hospital, School of Medicine Southeast University, NO. 87 Ding Jia Qiao, Nanjing 210003, Jiangsu, China. ${ }^{2}$ Multidisciplinary Team (MDT) for Geriatric Hip Fracture Management Zhongda Hospital, School of Medicine Southeast University, Nanjing, Jiangsu, China. ${ }^{3}$ School of Medicine, Southeast University, Nanjing, Jiangsu, China. ${ }^{4}$ Orthopaedic Trauma Institute (OTI), Southeast University, Nanjing, Jiangsu, China. ${ }^{5}$ Trauma Center Zhongda Hospital, School of MedicineSoutheast University, Nanjing, Jiangsu, China. ${ }^{6}$ Department of Orthopedics the First Medical Center, Chinese PLA General Hospital, No. 28 Fuxing Road, Beijing 100853, China.

Received: 21 October 2021 Accepted: 31 December 2021

Published online: 01 March 2022

\section{References}

1. Zhang YW, Lu PP, Li YJ, Dai GC, Chen MH, Zhao YK, Cao MM, Rui YF. Prevalence, Characteristics, and Associated Risk Factors of the Elderly with Hip Fractures: A Cross-Sectional Analysis of NHANES 2005-2010. Clin Interv Aging. 2021;16:177-85.

2. Zhang YW, Lu PP, Li YJ, Dai GC, Cao MM, Xie T, Zhang C, Shi L, Rui YF. Low dietary choline intake is associated with the risk of osteoporosis in elderly individuals: a population-based study. Food Funct. 2021;12(14):6442-51.

3. Xiao YP, Shu DP, Bei MJ, Ji T, Kan WS, Li SG. The clinical application of a novel method of internal fixation for femoral neck fractures-dynamic locking compression system. J Orthop Surg Res. 2018;13(1):131.

4. Dolatowski FC, Hoelsbrekken SE. Eight orthopedic surgeons achieved moderate to excellent reliability measuring the preoperative posterior tilt angle in 50 Garden-I and Garden-II femoral neck fractures. J Orthop Surg Res. 2017;12(1):133. 
5. Búcs G, Dandé Á, Patczai B, Sebestyén A, Almási R, Nöt LG, Wiegand N: Bipolar hemiarthroplasty for the treatment of femoral neck fractures with minimally invasive anterior approach in elderly. Injury 2020.

6. Hofmann-Fliri L, Nicolino TI, Barla J, Gueorguiev B, Richards RG, Blauth M, Windolf $\mathrm{M}$. Cement augmentation of implants-no general cure in osteoporotic fracture treatment. A biomechanical study on non-displaced femoral neck fractures. J Orthop Res. 2016:34(2):314-9.

7. Taha ME, Audigé L, Siegel G, Renner N. Factors predicting secondary displacement after non-operative treatment of undisplaced femoral neck fractures. Arch Orthop Trauma Surg. 2015;135(2):243-9.

8. Rzesacz EH, Weinberg AM, Reilmann H. Covered osteosynthesis through cannulated screws in medial Garden type I and II femoral neck fractures. Unfallchirurg. 1995:98(9):478-82.

9. Cserháti P, Kazár G, Manninger J, Fekete K, Frenyó S. Non-operative or operative treatment for undisplaced femoral neck fractures: a comparative study of 122 non-operative and 125 operatively treated cases. Injury. 1996;27(8):583-8.

10. Hartel MJ, Petersik A, Schmidt A, Kendoff D, Nüchtern J, Rueger JM, Lehmann W, Grossterlinden LG. Determination of Femoral Neck Angle and Torsion Angle Utilizing a Novel Three-Dimensional Modeling and Analytical Technology Based on CT Datasets. PloS one. 2016;11(3):e0149480.

11. Du CL, Ma XL, Zhang T, Zhang HF, Wang CG, Zhao F, Ma JX, Fu X, Li ZJ. Reunderstanding of garden type I femoral neck fractures by 3-dimensional reconstruction. Orthopedics. 2013;36(6):820-5.

12. Zhang RY, Su XY, Zhao JX, Li JT, Zhang LC, Tang PF. Three-dimensional morphological analysis of the femoral neck torsion angle-an anatomical study. J Orthop Surg Res. 2020;15(1):192.

13. Mutasa S, Varada S, Goel A, Wong TT, Rasiej MJ. Advanced Deep Learning Techniques Applied to Automated Femoral Neck Fracture Detection and Classification. J Digit Imaging. 2020;33(5):1209-17.

14. Kim JW, Byun SE, Chang JS. The clinical outcomes of early internal fixation for undisplaced femoral neck fractures and early full weight-bearing in elderly patients. Arch Orthop Trauma Surg. 2014;134(7):941-6.

15. Viberg B, Kold S, Brink O, Larsen MS, Hare KB, Palm H. Is arthroplaSty bEtter than interNal fixation for undiSplaced femoral nEck fracture? A national pragmatic RCT: the SENSE trial. BMJ open. 2020;10(10):e038442.

16. Wolf O, Sjöholm P, Hailer NP, Möller M, Mukka S. Study protocol: HipSTHeR - a register-based randomised controlled trial - hip screws or (total) hip replacement for undisplaced femoral neck fractures in older patients. BMC Geriatr. 2020;20(1):19.

17. Palm H, Gosvig K, Krasheninnikoff M, Jacobsen S, Gebuhr P. A new measurement for posterior tilt predicts reoperation in undisplaced femoral neck fractures: 113 consecutive patients treated by internal fixation and followed for 1 year. Acta Orthop. 2009;80(3):303-7.

18. Yamamoto T, Kobayashi Y, Nonomiya H. Undisplaced femoral neck fractures need a closed reduction before internal fixation. European journal of orthopaedic surgery \& traumatology : orthopedie traumatologie. 2019:29(1):73-8

19. Chen WC, Yu SW, Tseng IC, Su JY, Tu YK, Chen WJ. Treatment of undisplaced femoral neck fractures in the elderly. The Journal of trauma. 2005;58(5):1035-9 (discussion 1039).

20. Hopkins C, Genant HK. Editorial for Guidelines for clinical diagnosis and treatment of osteonecrosis of the femoral head in adults (2019 version). Journal of orthopaedic translation. 2020;21:A1.

21. Park CW, Lim SJ, Kim JH, Park YS. Hip resurfacing arthroplasty for osteonecrosis of the femoral head: Implant-specific outcomes and risk factors for failure. Journal of orthopaedic translation. 2020;21:41-8.

22. Kain MS, Marcantonio AJ, Iorio R. Revision surgery occurs frequently after percutaneous fixation of stable femoral neck fractures in elderly patients. Clin Orthop Relat Res. 2014;472(12):4010-4.

23. Lee KB, Howe TS, Chang HC. Cancellous screw fixation for femoral neck fractures: one hundred and sixteen patients. Ann Acad Med Singapore. 2004;33(2):248-51.

24. Manohara R, Liang S, Huang D, Krishna L. Cancellous screw fixation for undisplaced femoral neck fractures in the elderly. J Orthop Surg (Hong Kong). 2014;22(3):282-6.

25. Chiu KY, Pun WK, Luk KD, Chow SP. Cancellous screw fixation for subcapital femoral neck fractures. J R Coll Surg Edinb. 1994;39(2):130-2.

26. Dolatowski FC, Frihagen F, Bartels S, Opland V, ŠaltytèBenth J, Talsnes O, Hoelsbrekken SE, Utvåg SE. Screw Fixation Versus Hemiarthroplasty for
Nondisplaced Femoral Neck Fractures in Elderly Patients: A Multicenter Randomized Controlled Trial. The Journal of bone and joint surgery American. 2019;101(2):136-44.

27. Watson A, Zhang Y, Beattie S, Page RS. Prospective randomized controlled trial comparing dynamic hip screw and screw fixation for undisplaced subcapital hip fractures. ANZ J Surg. 2013;83(9):679-83.

28. Makki D, Mohamed AM, Gadiyar R, Patterson M. Addition of an antirotation screw to the dynamic hip screw for femoral neck fractures. Orthopedics. 2013;36(7):e865-868.

29. Biber R, Brem M, Bail HJ. Targon Femoral Neck for femoral-neck fracture fixation: lessons learnt from a series of one hundred and thirty five consecutive cases. Int Orthop. 2014;38(3):595-9.

30. Griffin XL, Parsons N, Achten J, Costa ML. the Targon femoral neck hip screw versus cannulated screws for internal fixation of intracapsular fractures of the hip: a randomised controlled trial. The bone \& joint journal. 2014;96-b(5):652-7.

31. Alshameeri Z, Elbashir M, Parker MJ. The outcome of intracapsular hip fracture fixation using the Targon Femoral Neck (TFN) locking plate system or cannulated cancellous screws: A comparative study involving 2004 patients. Injury. 2017:48(11):2555-62.

32. van Walsum ADP, Vroemen J, Janzing HMJ, Winkelhorst T, Kalsbeek J, Roerdink WH. Low failure rate by means of DLBP fixation of undisplaced femoral neck fractures. European journal of trauma and emergency surgery : official publication of the European Trauma Society. 2017:43(4):475-80

33. Chiang MH, Wang CL, Fu SH, Hung CC, Yang RS. Does fully-threaded Headless Compression Screw provide a length-stable fixation in undisplaced femoral neck fractures? Asian J Surg. 2019;42(1):320-5.

34. Overmann AL, Richards JT, O'Hara NN, D'Alleyrand JC, Slobogean GP. Outcomes of elderly patients with nondisplaced or minimally displaced femoral neck fractures treated with internal fixation: A systematic review and meta-analysis. Injury. 2019;50(12):2158-66.

35. Barquet A, Mayora G, Guimaraes JM, Suárez R, Giannoudis PV. Avascular necrosis of the femoral head following trochanteric fractures in adults: a systematic review. Injury. 2014;45(12):1848-58.

36. Morimoto M, Takahashi Y, Kubo T, Sugiura K, Tamaki Y, Toki S, Suganuma K, Inoue K, Adachi K, Chikawa T, et al. Prognostic value of dynamic MRI positive enhancement integral color mapping in osteosynthesis of undisplaced femoral neck fractures. Journal of orthopaedic science : official journal of the Japanese Orthopaedic Association. 2017;22(4):722-5.

37. Gjertsen JE, Dybvik E, Furnes O, Fevang JM, Havelin LI, Matre K, Engesæter LB. Improved outcome after hip fracture surgery in Norway. Acta Orthop. 2017;88(5):505-11.

38. Lin JC, Liang WM. Outcomes after fixation for undisplaced femoral neck fracture compared to hemiarthroplasty for displaced femoral neck fracture among the elderly. BMC Musculoskelet Disord. 2015;16:199.

39. Lu Q, Tang G, Zhao X, Guo S, Cai B, Li Q. Hemiarthroplasty versus internal fixation in super-aged patients with undisplaced femoral neck fractures: a 5-year follow-up of randomized controlled trial. Arch Orthop Trauma Surg. 2017;137(1):27-35.

40. Mukka S, Knutsson B, Krupic F, Sayed-Noor AS. The influence of cognitive status on outcome and walking ability after hemiarthroplasty for femoral neck fracture: a prospective cohort study. European journal of orthopaedic surgery \& traumatology : orthopedie traumatologie. 2017;27(5):653-8.

41. Olofsson B, Stenvall M, Lundström M, Gustafson Y, Svensson O. Mental status and surgical methods in patients with femoral neck fracture. Orthop Nurs. 2009;28(6):305-13.

42. Bjørgul K, Reikerås O. Outcome of undisplaced and moderately displaced femoral neck fractures. Acta Orthop. 2007;78(4):498-504.

43. Kim SJ, Park HS, Lee DW. Complications after internal screw fixation of nondisplaced femoral neck fractures in elderly patients: A systematic review. Acta Orthop Traumatol Turc. 2020;54(3):337-43.

44. Nyholm AM, Palm H, Sandholdt H, Troelsen A, Gromov K. Risk of reoperation within 12 months following osteosynthesis of a displaced femoral neck fracture is linked mainly to initial fracture displacement while risk of death may be linked to bone quality: a cohort study from Danish Fracture Database. Acta Orthop. 2020;91(1):1-75.

45. Zamora T, Klaber I, Ananias J, Bengoa F, Botello E, Amenabar P, Schweitzer $D$. The influence of the CT scan in the evaluation and treatment of nondisplaced femoral neck fractures in the elderly. J Orthop Surg (Hong Kong). 2019;27(2):2309499019836160. 
46. Richards JT, Overmann AL, O'Hara NN, D'Alleyrand JC, Slobogean GP. Internal Fixation Versus Arthroplasty for the Treatment of Nondisplaced Femoral Neck Fractures in the Elderly: A Systematic Review and MetaAnalysis. J Orthop Trauma. 2020;34(1):42-8.

47. Yong TM, Austin DC, Molloy IB, Kunkel ST, Jevsevar DS, Gitajn IL. Screw Fixation Versus Hemiarthroplasty for Nondisplaced Femoral Neck Fractures in the Elderly: A Cost-Effectiveness Analysis. J Orthop Trauma. 2020;34(7):348-55.

48. You D, Sepehri A, Kooner S, Krzyzaniak H, Johal H, Duffy P, Schneider P, Powell J. Outcomes of total hip arthroplasty using dual mobility components in patients with a femoral neck fracture. The bone \& joint journal. 2020;102-b(7):811-21.

49. Boelch SP, Jordan MC, Meffert RH, Jansen H. Comparison of open reduction and internal fixation and primary total hip replacement for osteoporotic acetabular fractures: a retrospective clinical study. Int Orthop. 2017:41(9):1831-7.

50. Lamb JN, Matharu GS, Redmond A, Judge A, West RM, Pandit HG. Risk Factors for Intraoperative Periprosthetic Femoral Fractures During Primary Total Hip Arthroplasty. An Analysis From the National Joint Registry for England and Wales and the Isle of Man. The Journal of arthroplasty. 2019;34(12):3065-3073.e3061.

51. Burchard R, Burazin K, Soost C, Heinz D, Leicht D, Bouillon B, Lahner M. Computer-aided planning with exact implementation into surgical technique in TKA is as accurate as intraoperative navigation. Technology and health care : official journal of the European Society for Engineering and Medicine. 2018;26(3):515-22.

52. Dong X-P, Zhang Y-W, Pei Y-J, Wang Z, Zhang X-X, Yu X-L, Ai Z-Z, Mei Y-X, $\mathrm{Li} J$ JN. Three-dimensional printing for the accurate orthopedics: clinical cases analysis. Bio-Design and Manufacturing. 2020;3(2):122-32.

53. Zhang YW, Deng L, Zhang XX, Yu XL, Ai ZZ, Mei YX, He F, Yu H, Zhang $L$, Xiao X, et al. Three-Dimensional Printing-Assisted Cervical Anterior Bilateral Pedicle Screw Fixation of Artificial Vertebral Body for Cervical Tuberculosis. World neurosurgery. 2019;127:25-30.

54. Zhang YW, Xiao X, Gao WC, Xiao Y, Zhang SL, Ni WY, Deng L. Efficacy evaluation of three-dimensional printing assisted osteotomy guide plate in accurate osteotomy of adolescent cubitus varus deformity. J Orthop Surg Res. 2019;14(1):353.

55. Zhang YW, Xiao X, Xiao Y, Chen X, Zhang SL, Deng L. Efficacy and Prognosis of 3D Printing Technology in Treatment of High-Energy TransSyndesmotic Ankle Fracture Dislocation - "Log-Splitter" Injury. Medical science monitor : international medical journal of experimental and clinical research. 2019;25:4233-43.

56. Zheng P, Yao Q, Xu P, Wang L. Application of computer-aided design and 3D-printed navigation template in Locking Compression Pediatric Hip Plate(TM) placement for pediatric hip disease. Int J Comput Assist Radiol Surg. 2017;12(5):865-71.

\section{Publisher's Note}

Springer Nature remains neutral with regard to jurisdictional claims in published maps and institutional affiliations.

Ready to submit your research? Choose BMC and benefit from:

- fast, convenient online submission

- thorough peer review by experienced researchers in your field

- rapid publication on acceptance

- support for research data, including large and complex data types

- gold Open Access which fosters wider collaboration and increased citations

- maximum visibility for your research: over $100 \mathrm{M}$ website views per year

At BMC, research is always in progress.

Learn more biomedcentral.com/submissions 